\title{
Triplet dynamics and charge carrier trapping in triplet-emitter doped conjugated polymers
}

\author{
A. Kadashchuk ${ }^{a, d, *}$, S. Schols ${ }^{a, b, c}$, A. Vakhnin ${ }^{\text {d }}$, J. Genoe ${ }^{a}$, P. Heremans ${ }^{a, b}$ \\ ${ }^{a}$ IMEC v.z.w., SOLO-PME, Kapeldreef 75, B-3001 Leuven, Belgium \\ ${ }^{\mathrm{b}}$ Katholieke Universiteit Leuven, Electrical Engineering Department, B-3001 Leuven, Belgium \\ ${ }^{\mathrm{C}}$ Aspirant at the FWO-Vlaanderen, Egmontstraat 5, 1000 Brussels Belgium \\ ${ }^{d}$ Institute of Physics, Natl. Acad. Sci. of Ukraine, Prospekt Nauki 46, 03028 Kiev, Ukraine
}

\section{A R T I C L E I N F O}

Article history:

Received 20 October 2008

Accepted 19 January 2009

Available online 23 January 2009

\section{Keywords:}

Conjugated polymer

Phosphorescence

Metal-organic complex

Energy transfer

Charge carrier trapping

Time-resolved photoluminescence

Thermally-stimulated luminescence

\begin{abstract}
A B S T R A C T
Phosphorescent $(\mathrm{Ph})$ properties and charge carrier trapping have been studied in conjugated polymer CNPPP with incorporated red-emitting Btp $2 \mathrm{Ir}(\mathrm{acac})$ metal-organic complex by time-resolved photoluminescence and thermally-stimulated luminescence (TSL) techniques. We characterized intrinsic $\mathrm{Ph}$ of CNPPP matrix and dynamics of triplet excitations of $B_{2} p_{2} \operatorname{Ir}(\mathrm{acac})$ confined by the polymer host. Combined studies of time and intensity dependence of guest $\mathrm{Ph}$ have demonstrated that the observed decrease in the Ph efficiency in CNPPP:Btp ${ }_{2} \operatorname{Ir}(\mathrm{acac})$ system at increasing excitation intensity is dominated by mutual host-guest triplet-triplet annihilation. We observed $\mathrm{Ph}$ spectral diffusion effects at $10 \mathrm{wt} \%$ of Btp $\mathrm{IIr}_{2}$ (acac) dispersed in a polymer matrix, which is a proof for the triplet excitons migration though the manifold of triplet-emitter sites, and which governs the Ph concentration quenching effect. TSL measurements have provided direct evidence that the triplet-emitter molecules create a deep charge trap in the conjugated polymer and allowed trap characterization.
\end{abstract}

(c) 2009 Elsevier B.V. All rights reserved.

\section{Introduction}

Organic light-emitting diodes (OLEDs) have been extensively investigated for full-color plat-panel display applications and illumination light sources because of their merits of high luminance, low drive voltage, and variety of emission colors. Internal quantum efficiency of electro-fluorescence OLEDs is limited to be around $25 \%$ according to simple spin statistics [1]. In order to overcome this efficiency limit of fluorescent OLEDs, phosphorescent emitters doped into host material have been used. Phosphorescent emitters are low-molecular weight phosphorescent dye molecules incorporating a heavy metal atom with strong spin-orbit coupling that mixed singlet and triplet states. The radiative decay of triplet states becomes allowed and the efficiency of intersystem crossing is also enhanced. As result, the lowest triplet state is efficiently populated and produces light emission with large quantum yield. Phosphorescent emitters in both small organic molecule hosts and polymer hosts allow for harvesting singlet and triplet excitons and, therefore, internal quantum efficiency of the OLED devices can be greatly enhanced approaching $100 \%$ [2].

\footnotetext{
* Corresponding author. Address: Institute of Physics, Natl. Acad. Sci. of Ukraine, Prospekt Nauki 46, 03028 Kiev, Ukraine.

E-mail addresses: kadash@iop.kiev.ua, kadashchuk@yahoo.com (A. Kadashchuk).
}

For the preparation of polymer electro-phosphorescent polymer light-emitting diodes, the commonly used concept is to blend a low-molecular weight phosphorescent emitter into a proper polymer matrix. Transfer of excited state energy thus plays an important role in the operation of these devices. Singlet and triplet excitons can be first generated by electron-hole recombination in the polymer host and then transfer their energy to the dopant. Alternatively, the triplet state of the phosphorescent emitter may be formed by charge transfer from the host followed by charge recombination at the guest molecule. In both cases, the singlet and triplet energy levels of the host have to be well above the triplet state of the guest emitter to be efficient and prevent back transfer. The actual transfer of excitation to the guest molecule can occur via different mechanisms: Förster transfer of singlet excitons generated on the polymer matrix to the guest, Dexter transfer of both singlet and triplet excitons generated on the host to the dopant, as well as the direct generation of singlet and triplet excitons on the guest $[3,4]$. A specific feature of devices based on phosphorescence is that long phosphorescent $(\mathrm{Ph})$ lifetimes leads to saturation of emissive sites, and annihilation of triplet excitations may also cause significant efficiency losses. As a result, efficiency of such OLED devices tends to decrease at high current densities [5].

Recently, a comprehensive study has been performed to investigate triplet dynamics in ladder-type methyl-poly(para-phenylene) (MeLPPP) doped by platinum(II) octaethylporphine (PtOEP) complex [6-8]. Since both the $S_{1}$ and $T_{1}$ levels of the dopant are 
below those of the matrix [9-11] both Förster-type host-quest singlet-singlet and Dexter-type triplet-triplet energy transfer can be envisaged. Triplet-triplet annihilation is believed to be one of the major quenching mechanisms in phosphorescent OLEDs [12]. The longer lifetime for triplet excitons actually diminishes one of the advantages of dye doping of organic light-emitting devices, the ability to eliminate concentration quenching. One way to solve these problems is to use dopants with shorter triplet exciton lifetime. Therefore Ir complexes are more attractive candidates than platinum porphyrins owing to about one order of magnitude shorter lifetimes, which typically range from $1 \mu \mathrm{s}$ to $14 \mu \mathrm{s}$.

In this work we explore the phosphorescent properties of the host-guest system based on red-light-emitting bis[2-(2'-benzothienyl)pyridinato- $\mathrm{N}, \mathrm{C}^{3^{\prime}}$ ] (acetylacetonate) iridium $\left(\mathrm{Btp}_{2} \operatorname{Ir}(\mathrm{acac})\right.$ ) (Btp $2 \operatorname{Ir}(\mathrm{acac})$ ) doped in poly[1,4-bis(6'-cyano-6'-methylheptyloxy) phenylene] (CNPPP). Similarly to the above MeLPPP/PtOEP hostguest system, both the $S_{1}$ and $T_{1}$ levels of the Btp ${ }_{2} \operatorname{Ir}$ (acac) dopant are below those of the CNPPP polymer matrix, however the phosphorescent lifetime of $\mathrm{Btp}_{2} \mathrm{Ir}$ (acac) is tenfold shorter than that of PtOEP. We demonstrate that this results in different mechanisms dominated $\mathrm{Ph}$ properties. We also present direct evidence that the phosphorescent metal-organic complexes do act as charge traps and characterized these traps by means of charge trapping spectroscopy. In addition, it confirmed the notion that metal-organic complexes behave electronically not different from conventional all-organic small molecules.

\section{Experimental}

CNPPP was purchased from H.W. Sands Corp. and the tripletemitter compound $B t_{2} \operatorname{Ir}(\mathrm{acac})$ from American Dye Source Inc. The structural formulas of these compounds are shown in Fig. 1. All materials were used as received. Films of polymer doped with triplet-emitter molecules were prepared by dissolving the appropriate ratios of $B \mathrm{tp}_{2} \operatorname{Ir}(\mathrm{acac})$ and CNPPP in toluene, and then spincoating the resulting solutions on a precleaned quartz substrate. After deposition, the films were dried in a nitrogen glove-box at room temperature. Film thickness was typically $200 \mathrm{~nm}$.

Spectroscopic measurements of prompt fluorescence (PF) and delayed emission as delayed fluorescence (DF) and phosphorescence $(\mathrm{Ph})$ of both frozen diluted solutions and films were carried out within a temperature range from $77 \mathrm{~K}$ to $300 \mathrm{~K}$, using the temperature regulating nitrogen cryostat. All measurements were done in nitrogen atmosphere. A nitrogen laser with pulse duration of $4 \mathrm{~ns}$ operated at $10 \mathrm{~Hz}$ was used for optical excitation at $337 \mathrm{~nm}$. The emission spectra were recorded using a triple-grating monochromator coupled to an intensified CCD camera (PI-MAX from Princeton Instruments) with a time gated, intensified diode array detector, which was synchronized by the electrical trigger of the
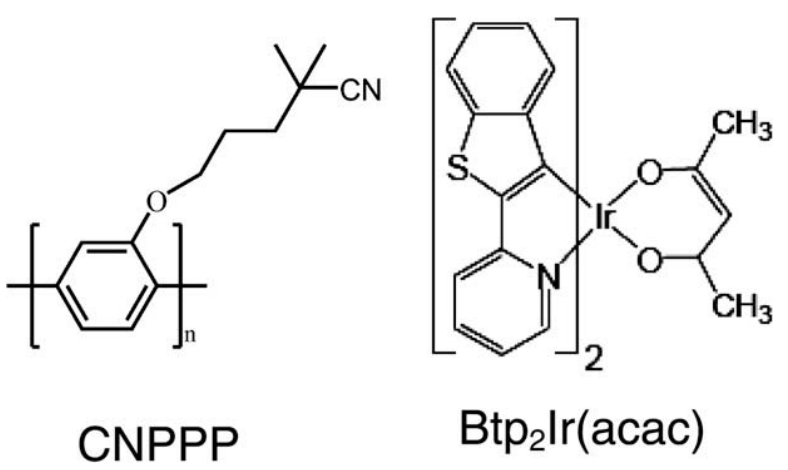

Fig. 1. The molecular structures of the CNPPP polymer and the red-light-emitting dye $\operatorname{Btp}_{2} \operatorname{Ir}(\mathrm{acac})$. laser. The detection window was selected between $100 \mathrm{~ns}$ and $10 \mathrm{~ms}$. A variable delay of $75 \mathrm{~ns}-10 \mathrm{~ms}$ after optical excitation allowed the detection of weak delayed luminescence after the intense prompt fluorescence. To increase the signal-to-noise ratio, spectra were accumulated by averaging over $100 \cdots 300$ pulses.

Thermally-stimulated luminescence (TSL) is the phenomenon of luminescent emission after removal of excitation under conditions of increasing temperature. Generally, in the TSL method the trapping states are first populated by photogeneration of charge carriers, usually at low temperatures in order to prevent a fast escape. Then, the trapped charge carriers are released by heating up the sample with a linear temperature ramp, while the luminescence due to radiative recombination is recorded as a function of temperature. If an energy distribution of the trap states exists, TSL spectra are a complicated convolution of contributions from different traps at different energies and fractional heating techniques have to be applied, which are based on cycling the sample with a large number of small temperature oscillations superimposed on a constant heating run. Thus, the TSL is a useful tool for determining the trap depths even when traps are not well separated in energy, or are continuously distributed, and it also allows analysis of the trap spectra even when they are complex.

TSL measurements were carried out using a home-built setup operable from $4.2 \mathrm{~K}$ to $350 \mathrm{~K}$ using a temperature controlled helium cryostat. After cooling down to $4.2 \mathrm{~K}$, the samples were photoexcited, usually for $30 \mathrm{~s}$, by a high-pressure $500 \mathrm{~W}$ mercury lamp with an appropriate set of glass optical filters for light selection. After the photoexcitation, the TSL was detected in a photoncounting mode with a cooled photomultiplier, positioned next to the cryostat window. The TSL measurements were performed either at a constant heating rate of $\beta=0.15 \mathrm{~K} / \mathrm{s}$ or in the fractional heating regime. The latter procedure allows the determination of trap depth when different groups of traps are not well separated in energy or are continuously distributed. The details of our TSL method were described previously $[13,14]$.

\section{Results}

\subsection{Photoluminescence studies}

\subsubsection{Pristine CNPPP films}

Fig. 2 (curve 1) shows spectra of the prompt fluorescence from a pristine CNPPP film registered during the laser pulse at $77 \mathrm{~K}$ and

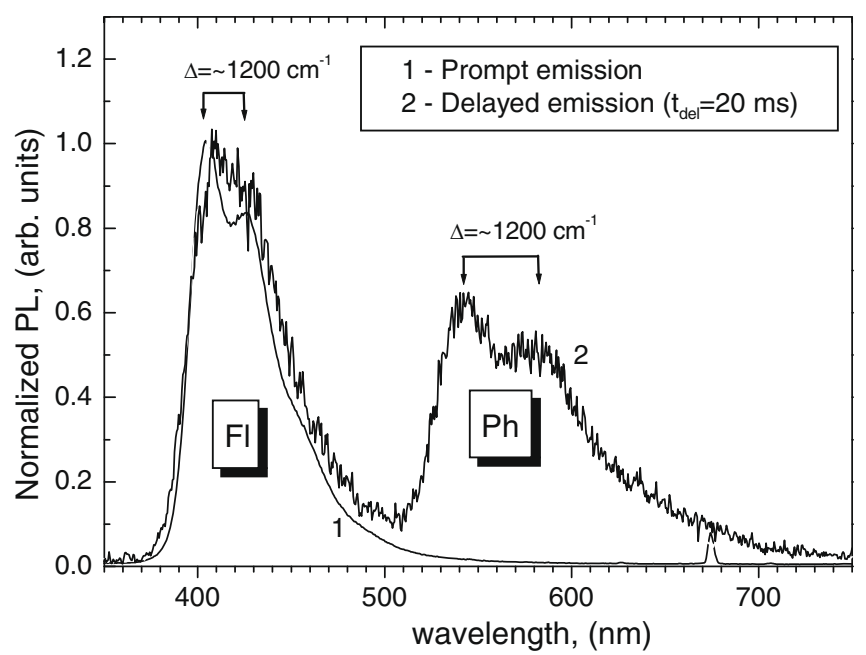

Fig. 2. Normalized spectra of prompt fluorescence (curve 1) and delayed emission (curve 2) from pristine CNPPP film at $77 \mathrm{~K}$. Delayed emission was measured with $20 \mathrm{~ms}$ delay time after the laser pulse and with gate width of $6 \mathrm{~ms}$. 
which consists of a main $S_{1} \rightarrow S_{0}$ band at $405 \mathrm{~nm}(3.08 \mathrm{eV})$ followed by a vibronic feature displaced by about $1200 \mathrm{~cm}^{-1}$. This spectrum coincides with steady-state PL spectra implying that the fluorescence in the range of $400-500 \mathrm{~nm}$, caused by the radiative decay of singlet excitons, is dominant in this material.

The delayed emission spectra of pristine CNPPP film detected by introducing a time delay $\left(t_{d e l}=20 \mathrm{~ms}\right.$ ) between the exciting laser pulse and the detection window of the registration system is depicted by curve 2 in Fig. 2 . In contrast to the prompt fluorescence spectra, the delayed emission from CNPPP exhibits two different components with different decay times and different spectral positions. The short wavelength component of the delayed emission is virtually identical to the prompt fluorescence spectrum. Thus it can be assigned to the delayed fluorescence (DF) from the $S_{1}$ state of CNPPP. The second slower decaying set of bands is shifted by $0.78 \mathrm{eV}$ with respect to the first peak of the DF, but has the same vibronic splitting of about $1200 \mathrm{~cm}^{-1}$ (Fig. 2, curve 2) as the fluorescence spectrum. It should be noted that this second longerwavelengths spectral component can only be seen in the delayed emission and shows all generic signatures of phosphorescence, principally similar to that previously found in other conjugated polymers as methyl-substituted ladder-type poly(para-phenylene) (MeLPPP) [15,16], ladder-type poly(para-phenylene carbazole) (LPPPC) [17] and polyfluorenes [18]. Therefore we assign this spectral part in the range of $520-700 \mathrm{~nm}$ to intrinsic phosphorescence $(\mathrm{Ph})$ from the $T_{1}$ state at $542 \mathrm{~nm}(2.3 \mathrm{eV})$ (Fig. 2, curve 2 ) of pristine CNPPP featuring a singlet-triplet $\left(S_{1}-T_{1}\right)$ splitting of about $\Delta E_{S T}=0.78 \mathrm{eV}$ which is a rather typical value for organic conjugated polymers [19].

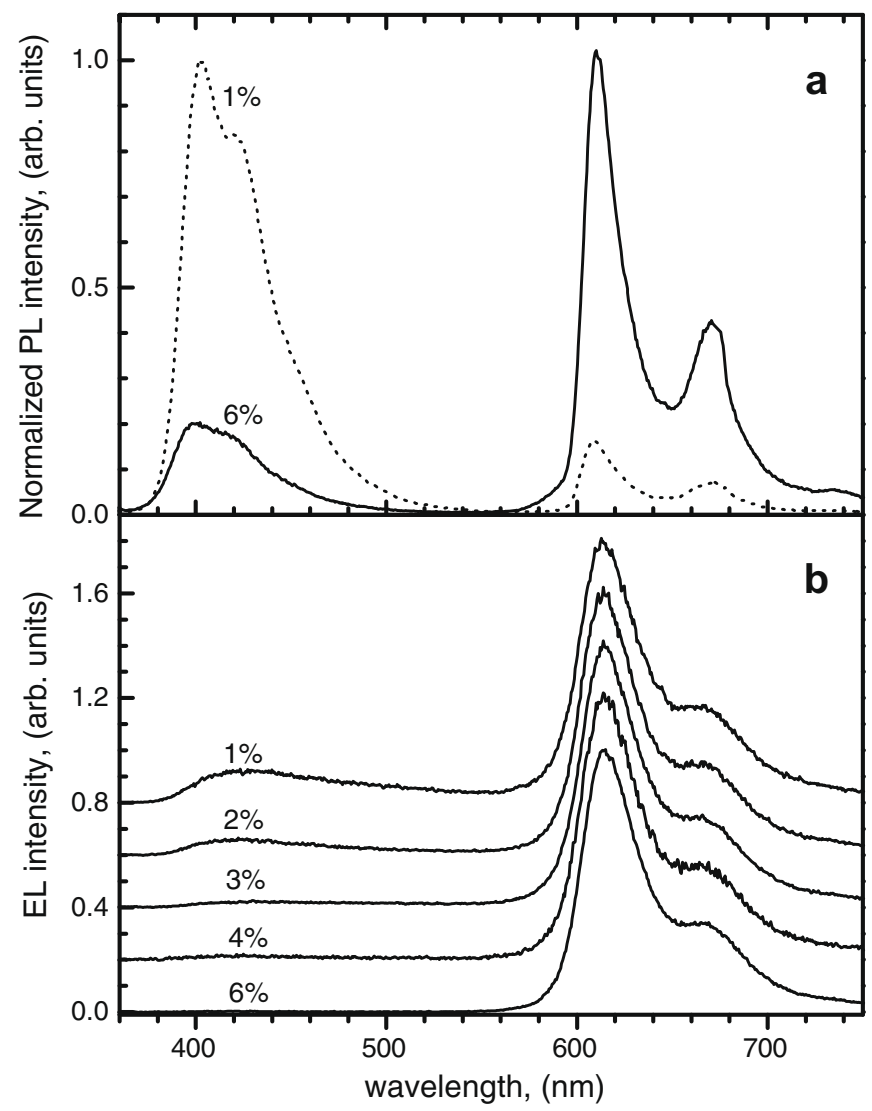

Fig. 3. (a) Steady-state PL spectra of CNPPP films doped with Btp ${ }_{2} \operatorname{Ir}(\mathrm{acac})$ at doping concentration of 1 and 6 wt.\% measured at $77 \mathrm{~K}$. (b) EL spectra of CNPPP: $\mathrm{Btp}_{2} \operatorname{Ir}(\mathrm{acac})$ films with different doping concentration of $\mathrm{Btp}_{2} \operatorname{Ir}(\mathrm{acac}$ ) (shown in Figure).

\subsubsection{CNPPP films doped with Btp $\operatorname{Ir}$ (acac)}

Fig. 3a shows normalized steady-state low-temperature PL spectra of CNPPP films doped with Btp $\mathrm{P}_{2} \operatorname{Ir}$ (acac) at different doping concentrations. As one can see, the PL spectra exhibit two components corresponding, respectively, to fluorescent emission from CNPPP host in the range from $400 \mathrm{~nm}$ to $500 \mathrm{~nm}$, and a set of red emission peaks of $\mathrm{Btp}_{2} \operatorname{Ir}(\mathrm{acac})$ phosphorescence. The phosphorescence of $\mathrm{Btp}_{2} \mathrm{Ir}(\mathrm{acac})$ shows a well-resolved spectrum with $T_{1} \rightarrow S_{0}$ band at $610 \mathrm{~nm}(2.05 \mathrm{eV})$ followed by a vibronic fine structure; the mechanism of $\mathrm{Ph}$ in this compound has been assigned before $[20,21]$ to the transition from ligand triplet ${ }^{3} \pi-\pi^{*}$ level. The relative contribution of the fluorescence emission of the CNPPP host reduces significantly with increasing $B \mathrm{P}_{2} \operatorname{Ir}(\mathrm{acac})$ concentration, as expected due to Förster singlet energy transfer from the host matrix to the dopant followed by intersystem crossing to the triplet state of the iridium complex [22]. However, even at dopant concentration as high as $6 \mathrm{wt}$ \% the host fluorescence is not completely quenched (Fig. 3a). Note that light absorption at $\lambda_{\text {exc }}=337 \mathrm{~nm}$ in studied CNPPP:Btp ${ }_{2} \operatorname{Ir}(\mathrm{acac})$ thin films is dominated by CNPPP host absorption at all considered dopant concentrations, therefore excitation of $\mathrm{Btp}_{2} \operatorname{Ir}(\mathrm{acac})$ molecules in this case could only be possible via energy transfer from the host matrix.

Electroluminescence (EL) spectra of CNPPP films doped with doping concentration of $\mathrm{Btp}_{2} \operatorname{Ir}(\mathrm{acac})$ varying from $1 \mathrm{wt} . \%$ to 6 wt.\% were also measured in devices with configuration ITO/PEDOT/CNPPP:Btp ${ }_{2} \operatorname{Ir}$ (acac)/LiF/Al and are shown in Fig. 3b. As one can see, in contrast to the PL emission spectra (Fig. 3a) a complete quenching of host EL emission occurs at notably lower Btp $\mathrm{P}_{2} \operatorname{Ir}$ (acac) doping levels, as low as $3 \mathrm{wt} . \%$. The EL quenching is commonly found to occur at much lower triplet-emitter concentration in a polymer host as compared to the PL emission and this has been attributed by many authors $[22,23]$ to the charge recombination taking place preferentially on triplet-emitter molecules, tacitly assuming therefore the efficient charge carrier trapping by the dopant species.

Fig. 4 presents time-resolved PL spectra of the CNPPP film doped with $0.05 \mathrm{wt} . \% \mathrm{Btp}_{2} \mathrm{Ir}$ (acac) recorded at $77 \mathrm{~K}$ over a very wide range of delay times after the laser pulse excitation (from $0.1 \mu \mathrm{s}$ to $800 \mu \mathrm{s}$ ) employing a large width of $1 \mathrm{~ms}$ of the gate window (so-called integration mode). As one can see, both DF of the host and $\mathrm{Ph}$ of the dopant contribute to the delayed emission

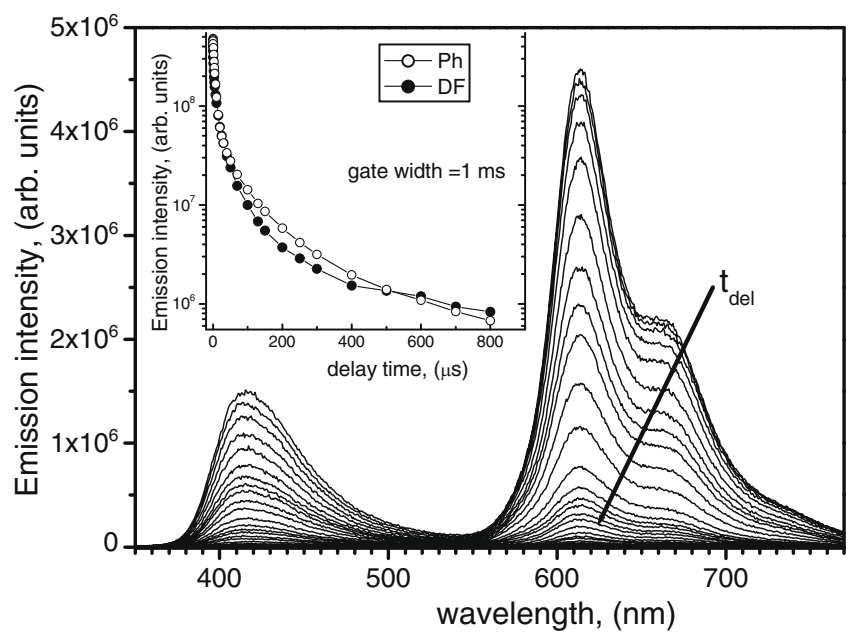

Fig. 4. Time-resolved PL spectra of the CNPPP film doped with $0.05 \mathrm{wt} . \%$ $\mathrm{Btp}_{2} \operatorname{Ir}(\mathrm{acac})$ at $80 \mathrm{~K}$. The delay time $t_{d e l}$ varies from $0.1 \mu$ s to $800 \mu \mathrm{s}$ at a constant gate width of $1 \mathrm{~ms}$. The inset shows the time dependence of DF and $\mathrm{Ph}$ intensity in the CNPPP:Btp $2 \operatorname{Ir}(\mathrm{acac})$. 
spectra presented in Fig. 4. However no intrinsic Ph of the CNPPP host at $542 \mathrm{~nm}$ (c.f. Fig. 2) could be observed in the CNPPP:Btp $2 \mathrm{Ir}$ (acac) host-guest system, implying that the host triplet excitations are efficiently quenched by the lower-energy $B t_{2} \operatorname{Ir}(\mathrm{acac})$ triplet state via Dexter mechanism. The time dependence of DF and Ph intensity in the CNPPP:Btp $\operatorname{Ir}(\mathrm{acac})$ is shown in the inset to Fig. 4. A remarkable observation is that $\mathrm{Ph}$ of $\mathrm{Btp}_{2} \mathrm{Ir}$ (acac) in a CNPPP matrix can be measured even at delay times much larger than the intrinsic Ph lifetime of $\operatorname{Btp}_{2} \operatorname{Ir}(\mathrm{acac})$, which is $\sim 7 \mu \mathrm{s}$ [24], implying a delay population mechanism of the dopant triplet level. With increasing $B \mathrm{Bp}_{2} \operatorname{Ir}(\mathrm{acac})$ concentration the reduction of the delayed fluorescence intensity of the polymer host has been observed that most probably can be attributed to the quenching of the host singlet excitations involved in DF emission.
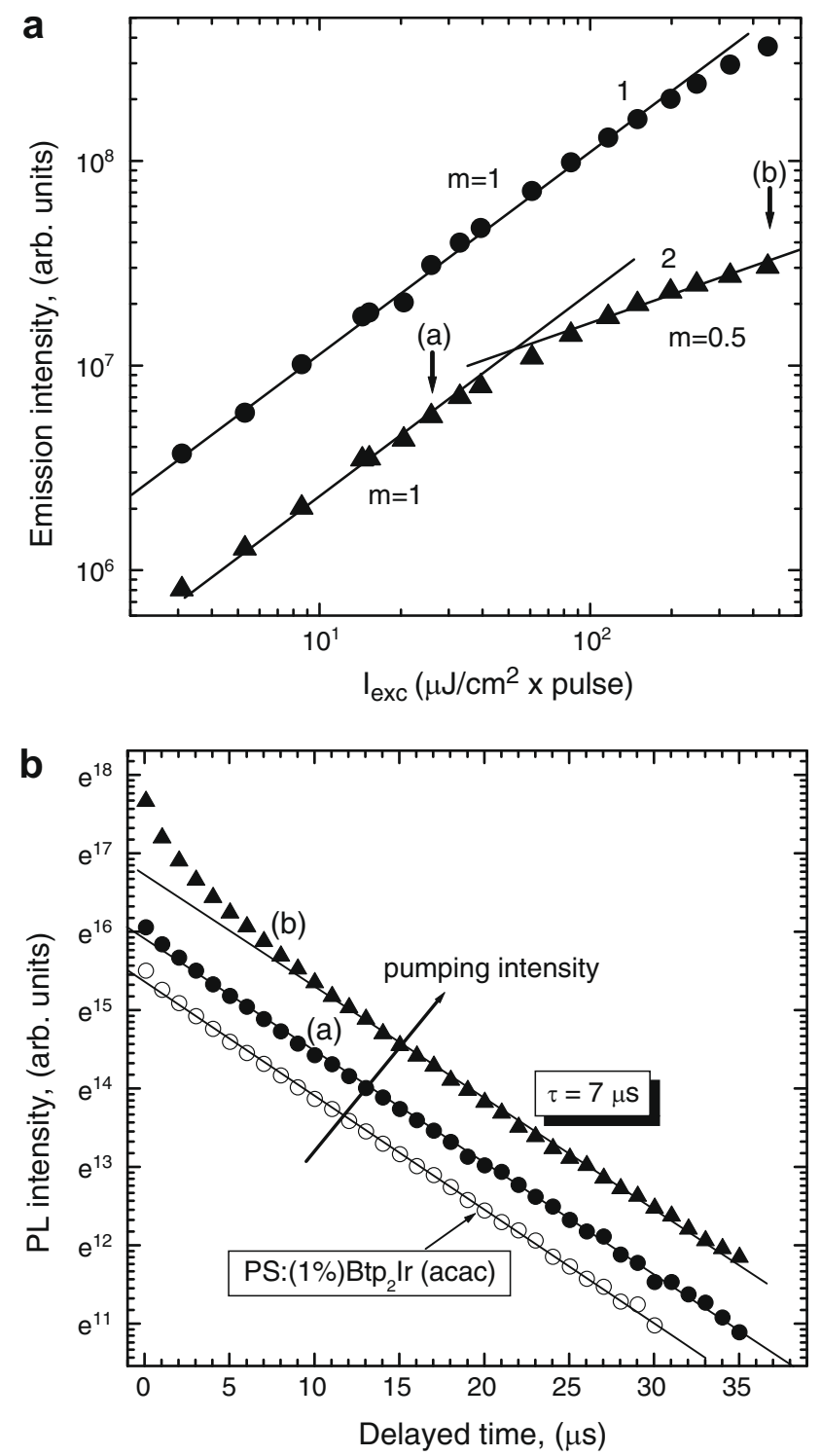

Fig. 5. (a) Dependence of fluorescence of CNPPP host (curve 1) and phosphorescence of $\mathrm{Btp}_{2} \operatorname{Ir}(\mathrm{acac})$ guest (curve 2) on excitation intensity at $80 \mathrm{~K}$ in CNPPP:(1\%)Btp 2 Ir(acac) film. Arrows depict the low- and high-laser power intensities at which the Ph decay kinetics presented in Fig. $5 \mathrm{~b}$ has been measured presented. (b) Time decay kinetics of Ph emission measured in CNPPP:(1\%)Btp 2 Ir(acac) film at low- and high-laser excitation intensity at $80 \mathrm{~K}$ (curve (a) and (b), respectively). The gate width was $0.1 \mu \mathrm{s}$. The $\mathrm{Ph}$ decay kinetics of $\operatorname{Btp}_{2} \operatorname{Ir}(\mathrm{acac})$ doped (1 wt.\%) into a polystyrene film is given by open circles (this curve is arbitrary shifted on the ordinate scale).
The intensity dependence of prompt fluorescent and Ph emission of CNPPP film doped with (1 wt.\%) Btp $2 \mathrm{r}$ (acac) upon laser excitation intensity is presented in Fig. 5a. The plotted emission intensities were obtained by integrating over the wavelength. The CNPPP fluorescence intensity varies approximately linearly with laser power (curve 1 ). The Ph of $\mathrm{Btp}_{2} \operatorname{Ir}(\mathrm{acac}$ ) behaves in a different way (Fig. 5a, curve 2): at low excitation intensity the dependence of $\mathrm{Ph}$ is a linear function $\left(I_{P h} \sim I_{\text {exc }}^{m}\right.$ where $\left.m=1\right)$, whereas at power densities of the excitation higher than $\sim 50 \mu \mathrm{J} /\left(\mathrm{cm}^{2} \times\right.$ Pulse $)$ a crossover to a slow square-root increase $(m=0.5)$ occurs. Such intensity dependence of $\mathrm{Ph}$ at high excitation densities is often considered as a signature of triplet-triplet annihilation ( $T-T$ annihilation) $\left(T_{1}+T_{1} \rightarrow S^{*}+S_{0}\right)[16,18]$ being a dominant mechanism for depletion of triplet reservoir in this case. It should be noted that the excitation intensity at which the above crossover is observed was found to shifts to somewhat lower intensities with increasing temperature as expected for a thermally activated diffusion migration of triplet excitations governing the $T-T$ annihilation.

Fig. $5 \mathrm{~b}$ presents the decay kinetics of phosphorescent emission of Btp $\mathrm{B}_{2} \operatorname{Ir}(\mathrm{acac})$ in the same CNPPP:(1\%)Btp $\operatorname{Ir}$ (acac) film as in Fig. 5a measured at low- and high-laser excitation intensity at $80 \mathrm{~K}$ (curve "a" and "b", respectively). The excitation intensities used here are indicated by arrows in Fig. 5a and these laser powers correspond to the regime of either a linear- or a square-root-Ph increase with increasing pump intensity. At low excitation intensity the Ph of $\mathrm{Btp}_{2} \operatorname{Ir}$ (acac) doped in a CNPPP matrix decays mono-exponentially over the time range studied featuring the lifetime of about $\tau=7 \mu$ s (Fig. 5b, curve "a”). At high excitation intensity (Fig. 5b, curve " $b$ "), the initial $\mathrm{Ph}$ decay during several microseconds after the laser pulse is fast. It is followed by the mono-exponential decay with the same lifetime of $7 \mu$ s at larger delay times. The latter behavior proves that $T-T$ annihilation does occur at short delay times after the excitation when triplets' concentration in the material is still large enough.

It should be noted that no deviation from the mono-exponential $\mathrm{Ph}$ decay with $\tau=7 \mu$ s was observed when $\mathrm{Btp}_{2} \operatorname{Ir}$ (acac) was doped into a polystyrene (PS) film, irrespective of the laser excitation intensity level (Fig. 5b, open cycles). The same mono-exponential $\mathrm{Ph}$ decay kinetics was also observed in frozen diluted solution of $\mathrm{Btp}_{2} \operatorname{Ir}(\mathrm{acac})$ in toluene suggesting that this is an intrinsic molecular property of this triplet-emitter compound, that was reported before [24].

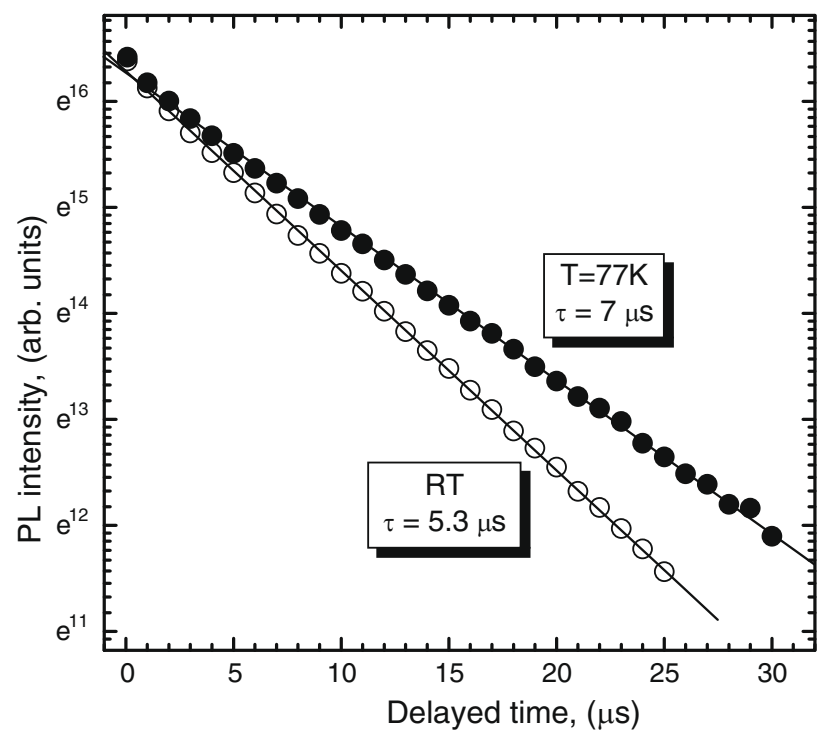

Fig. 6. Time decay kinetics of $\mathrm{Ph}$ emission measured in $\mathrm{PS}:(1 \%) B \mathrm{Bt}_{2} \mathrm{Ir}(\mathrm{acac})$ film at $80 \mathrm{~K}$ and room temperature. The gate width was $0.1 \mu \mathrm{s}$. 


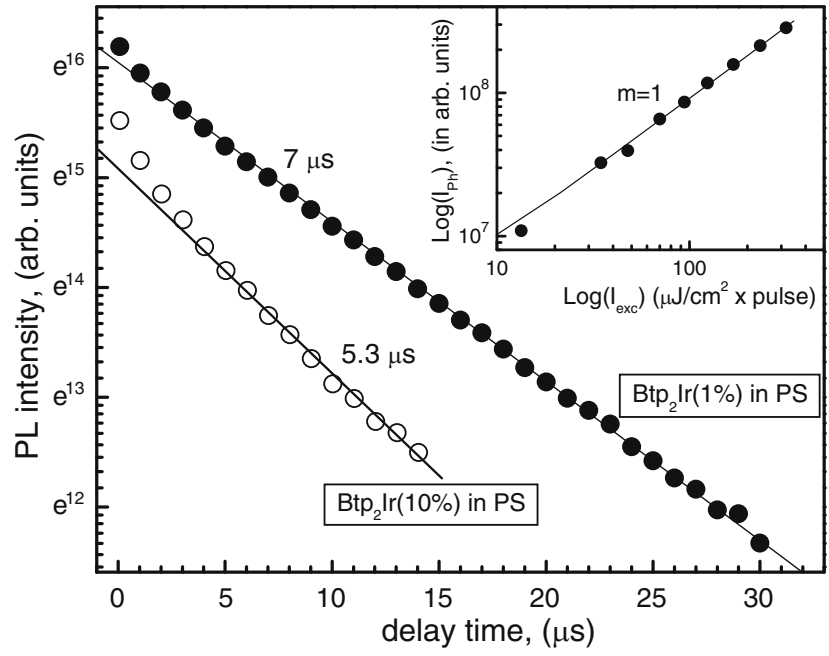

Fig. 7. Time decay kinetics of $\mathrm{Ph}$ emission measured in PS:Btp $\operatorname{Ir}(\mathrm{acac})$ films at 1 and $10 \mathrm{wt}$.\% concentrations of $\mathrm{Btp}_{2} \operatorname{Ir}(\mathrm{acac})$. The kinetics were measured at $80 \mathrm{~K}$ with a gate width of $0.1 \mu$ s. Inset: the dependence of Ph intensity in PS:(10\%)Btp $\operatorname{Ir}(\mathrm{acac})$ film upon the laser excitation intensity.

\subsubsection{Btp $\operatorname{Ir}$ (acac) doped into PS matrix}

In order to get an insight into intrinsic Ph properties of Btp $\mathrm{P}_{2} \mathrm{Ir}(-$ acac) we studied the $c w$ - and time-resolved PL of this triplet-emitter doped into polystyrene (PS) film. We consider here PS as an optically inert binder allowing matrix isolation of $B t p_{2} \operatorname{Ir}(\mathrm{acac}) \mathrm{mol}$ ecules. The Ph decay kinetics of $B t \mathrm{p}_{2} \operatorname{Ir}(\mathrm{acac})$ doped into PS films recorded at $80 \mathrm{~K}$ and room temperature are depicted in Fig. 6. The intrinsic lifetime of $\mathrm{Ph}$ emission decrease from $7 \mu \mathrm{s}$ at $80 \mathrm{~K}$ to about $5 \mu$ s when temperature increases to room temperature and this correlates with observed gradual decrease of Ph intensity of $B t p_{2} \operatorname{Ir}(\mathrm{acac})$ with elevating temperature (not shown here) suggesting that temperature-dependent nonradiative processes are active in this metal-organic complex.

Fig. 7 presents the low-temperature Ph decay kinetics of $B t p_{2} \operatorname{Ir}$ (acac) doped PS films at small- and relatively high-tripletemitter concentration, namely at 1 and $10 \mathrm{wt} . \%$. As one see, the apparent $\mathrm{Ph}$ lifetime is notably smaller $(\tau \approx 5.3 \mu \mathrm{s})$ for $10 \% \mathrm{Btp}_{2} \mathrm{Ir}$

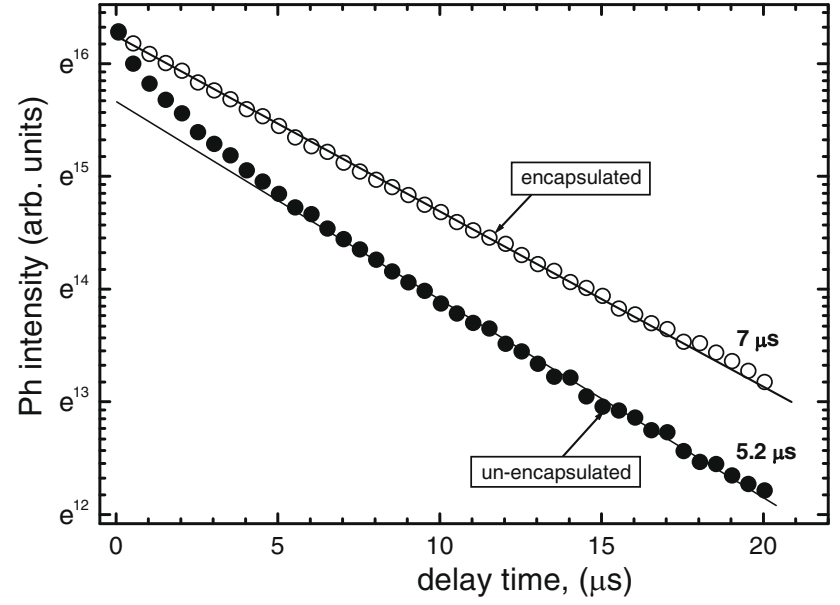

Fig. 9. Low-temperature phosphorescence decay kinetics of PS:Btp $\operatorname{Ir}(\mathrm{acac})$ ( $c=10$ wt.\%) film encapsulated between two quartz plates in the glove-box (curve 1) and for the film prepared from the same solution but exposed to the air before loading to the cryostat.

(acac) concentration comparing to concentration of $1 \%(\tau=7 \mu \mathrm{s})$. At the same time the excitation intensity dependence of $\mathrm{Ph}$ in PS:(10\%)Btp $2 \mathrm{Ir}(\mathrm{acac})$ varies linearly with excitation intensity in the considered laser power range (inset in Fig. 7) implying that $T-T$ annihilation is negligible in this case and cannot be responsible for the observed reduced lifetime at large triplet-emitter concentrations (concentration quenching effect).

Fig. 8 shows the profile of first Ph band $\left(T_{1} \rightarrow S_{0}\right)$ from Btp $\operatorname{Br}_{2} \mathrm{Ir}(\mathrm{a}-$ cac) in a frozen diluted toluene solution ( $c=10-3 \mathrm{wt} . \%)$ and from Btp $_{2} \operatorname{Ir}$ (acac) doped in PS film at $c=10 \mathrm{wt}$ \% measured at different delay time (Fig. 8a and b, respectively). The Ph peak position of $\mathrm{Btp}_{2} \mathrm{Ir}$ (acac) in frozen solution showed no peak shift (Fig. 8a), however we observed a gradual red-shift of the peak with increasing the delay time (Fig. 8b) in heavily doped PS films. The same redshift was observed for the vibronic replica peaks (not shown here). This is a direct observation of the so-called spectral diffusion effect of $\mathrm{Ph}$ spectra of $\mathrm{Btp}_{2} \operatorname{Ir}(\mathrm{acac})$ implying that triplet excitations are no longer confined on isolated $B \operatorname{p}_{2} \operatorname{Ir}(\mathrm{acac})$ molecules at the doping le-
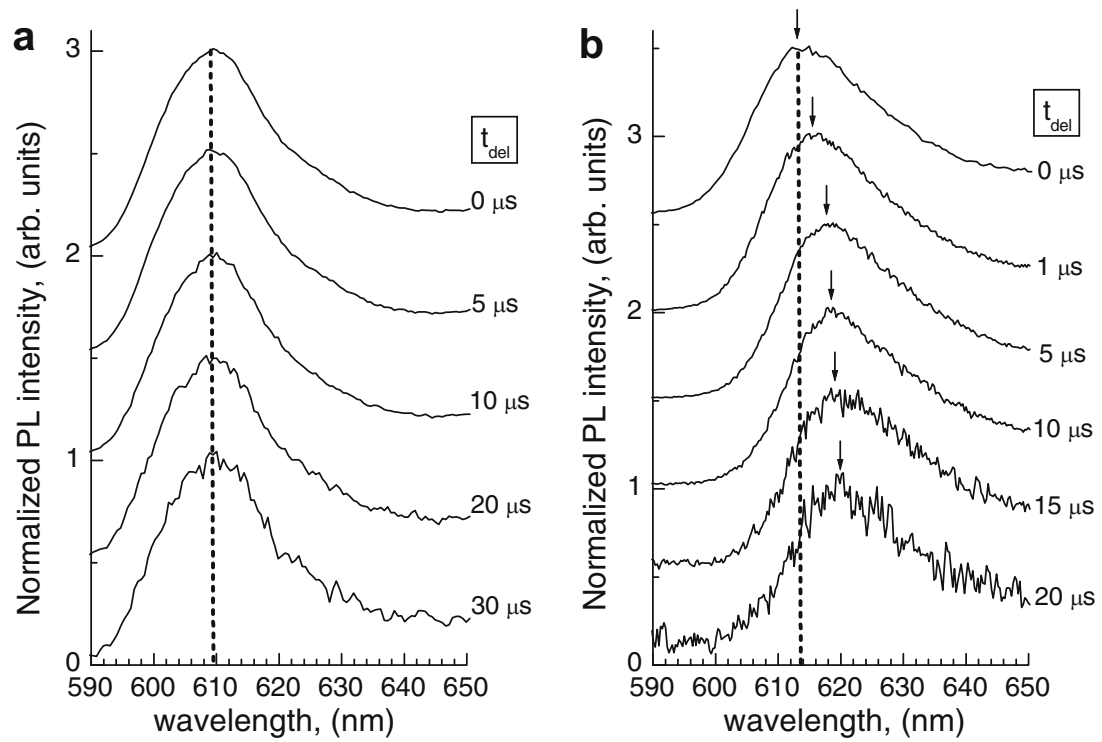

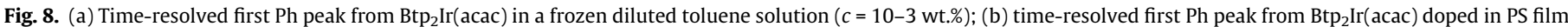
at $c=10 \mathrm{wt} . \%$. All spectra were measured at $80 \mathrm{~K}$ and normalized to the peak intensity. 
vel of $10 \%$ and they can migrate through the $B t p_{2} \operatorname{Ir}(\mathrm{acac})$ molecules manifold.

The results presented in Fig. 8 shed a light onto the observed apparent decrease of exciton lifetime of $B \mathrm{Bt}_{2} \operatorname{Ir}(\mathrm{acac})$ at increased dopant concentration in PS films (c.f. Fig. 7). Indeed, if triplet excitons are no longer confined on individual $\mathrm{Btp}_{2} \mathrm{Ir}(\mathrm{acac})$ molecules at $10 \%$ dopant concentration, as proven by the observed spectral diffusion effect, the probability of triplet quenching by accidental impurities, which has been suppressed in highly diluted system, does increase with concentration giving rise to the concentration quenching effect.

Obviously quenching sites which are operative in the film are dissolved in the film and could be oxygen molecules. Fig. 9 shows the low-temperature $\mathrm{Ph}$ decay kinetics of oxygen-free (curve 1) and exposed to air (curve 2) PS: $B \operatorname{tp}_{2} \operatorname{Ir}(\mathrm{acac})$ films at high(10 wt.\%) triplet-emitter concentration. As one can see, the Ph decay kinetics is perfectly mono-exponential in oxygen-free (never exposed to air and encapsulated in the glove-box) films (Fig. 9, curve 1) suggesting a negligible triplet quenching in them. The $\mathrm{Ph}$ decay kinetics in the PS:(10\%)Btp $\operatorname{Ir}$ (acac) film exposed to air deviates from linearity (curve 2) suggesting triplet quenching by oxygen.

\subsection{Thermally-stimulated luminescence in CNPPP doped with $\mathrm{Btp}_{2} \operatorname{Ir}(\mathrm{acac})$}

Fig. 10 presents the TSL glow curve of CNPPP film doped with Btp2Ir(acac) (curve 1). As one can see, TSL of CNPPP:Btp ${ }_{2} \operatorname{Ir}(\mathrm{acac})$ contains two major peaks, namely a low-temperature peak at $50 \mathrm{~K}$ and a high-temperature one with maximum at $220 \mathrm{~K}$. TSL of a pristine CNPPP film is shown for comparison (Fig. 10, curve 2) and it is dominated by the low-temperature TSL peak at $50 \mathrm{~K}$ while another weaker peak emerges at $\sim 150 \mathrm{~K}$. It should be mentioned that similar low-temperature peak centered at $T_{m} \approx 45-50 \mathrm{~K}$ has been commonly observed in many conjugated polymers as methyl-substituted ladder-type poly-para-phenylene (MeLPPP) [13], polyfluorenes [25], PPV derivatives [14], etc. and it arises due to the charge carrier release from the tail states of the intrinsic density-of-state (DOS) distribution of the polymer. The weaker TSL feature at $150 \mathrm{~K}$ in pristine CNPPP film (Fig. 10) is quite similar to that observed in polyfluorene polymers [25] and its relative intensity is rather sensitive to film preparation conditions. The weak TSL peak at $150 \mathrm{~K}$ is definitely due to moderately deep inherent charge

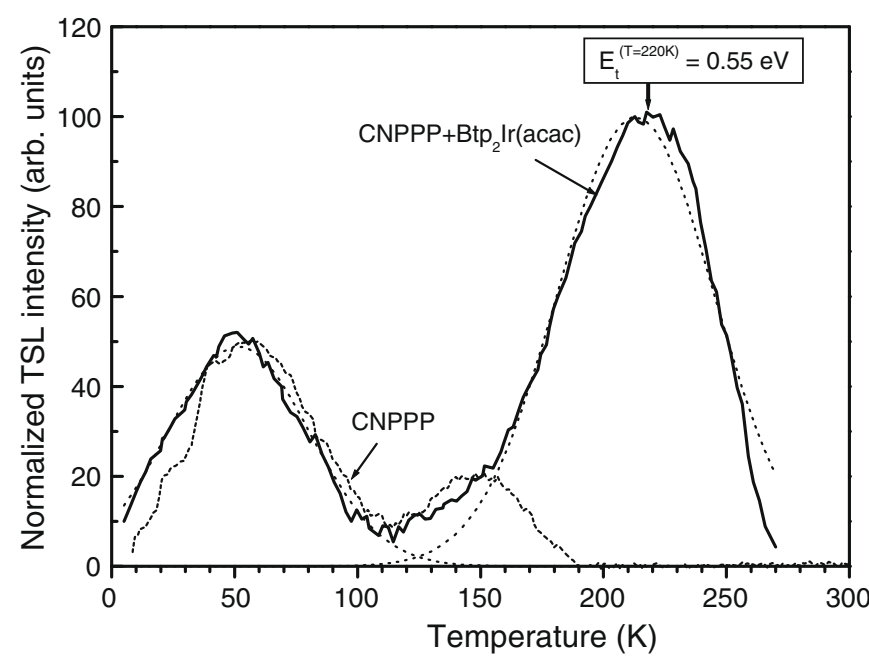

Fig. 10. The TSL glow curve of CNPPP film doped with $B \operatorname{tp}_{2} \operatorname{Ir}(\mathrm{acac})(c=5 \%)$ (red curve) and pristine CNPPP film (dashed curve) after excitation with $365 \mathrm{~nm}$ light at $4.2 \mathrm{~K}$. Doted curves depict fitting major TSC peaks using Gaussian functions. traps in CNPPP film, which could be of structural origin in this material, although study of the origin of this feature is beyond the scope of the present paper. It might be related to some sort of aggregates of polymer chains as it was found before for substituted polyfluorenes [25] and PPV derivatives [14].

Nonetheless, as it evidenced from Fig. 10, doping of the CNPPP host with $\mathrm{Btp}_{2} \mathrm{Ir}(\mathrm{acac})$ results in appearance of a new high-temperature TSL peak at $220 \mathrm{~K}$ suggesting that $\mathrm{Btp}_{2} \operatorname{Ir}(\mathrm{acac})$ molecules do create a rather deep trap. The activation energy of this deep trap is about $0.6 \mathrm{eV}$ as measured by the fractional TSL technique. This activation energy agrees well with the difference between HOMO level of CNPPP and that of $\operatorname{Btp}_{2} \operatorname{Ir}$ (acac), which is 5.7 [26] and $5.0 \mathrm{eV}$ [27], respectively. Thus, the TSL trapping spectroscopy has provided a direct evidence that $B \mathrm{t}_{2} \operatorname{Ir}(\mathrm{acac})$ phosphorescent complex create a relatively deep hole trap in CNPPP matrix. Electron trapping by $\mathrm{Btp}_{2} \operatorname{Ir}(\mathrm{acac})$ is not possible as the LUMO of the dopant (2.2 eV [27]) is higher than that of polymer matrix (2.3 eV [26]).

\section{Discussions}

Let us first discuss the triplet dynamics in the $B t p_{2} \operatorname{Ir}(\mathrm{acac})$ doped PS films. PS can be considered as an optically nonactivated polymer host as it did not show any light emission under the excitation used in this study. Therefore, Ph properties of PS:Btp $\mathrm{Br}_{2} \mathrm{Ir}$ (acac) films are virtually the same as those measured in frozen diluted solution. The Ph decay curve of PS doped with $1 \mathrm{wt} . \%$ $\mathrm{Btp}_{2} \operatorname{Ir}(\mathrm{acac})$ demonstrated a clear mono-exponential kinetics with the lifetime of 7 and $\sim 5.3 \mu$ s at 80 and $293 \mathrm{~K}$, respectively (Fig. 6), implying that the triplet excitations of $\mathrm{Btp}_{2} \mathrm{Ir}(\mathrm{acac})$ are efficiently confined by the PS host at such dopant concentration and that triplet quenching by impurities or via $T-T$ annihilation mechanism is negligible. Non-radiative quenching is active in this metal Ir complex [24] and responsible for shortening of the triplet state lifetime (Fig. 6) and eventually for decreasing the Ph intensity with elevating temperature.

An essential result of this study is the observed spectral diffusion effect (Fig. 8b) at 10 wt.\% of $\mathrm{Btp}_{2} \operatorname{Ir}$ (acac) doped in PS films. This observation is a direct proof for the triplet excitons migration process being controlled by the diffusion though the manifold triplet-emitter sites at such dopant level. This actually implies that triplets are no longer confined at $\operatorname{Btp}_{2} \operatorname{Ir}(\mathrm{acac})$ concentration of $10 \%$, which is close to that often use for fabrication of high-efficiency phosphorescent OLEDs. At such concentration, the triplets could be amenable to quenching. Indeed, minor traces of quenching impurities, such as triplet molecular oxygen or some intrinsic quenching defects in PS polymer, could become accessible to migrating triplets within the radiative life time of the triplet excitation [16]. The observation of migration of triplets at $10 \%$ concentration levels of $B_{1} \operatorname{Ir}(a c a c)$ is in excellent agreement with the recently proposed mechanism of dipole-dipole long-range Forster energy transfer in such phosphorescent materials [28] Indeed, Kawamura et al. [28] found that strong spin-orbital coupling increases the oscillator strength of the triplet-singlet transition and leads to a sufficiently high dipole-dipole transfer rate to enable the Forster energy transfer to be the dominant mechanism in these phosphorescent Ir-complexes. The characteristic $R^{-6}$ dependence of the concentration-quenching rate constant was observed that allows evaluation of the Forster radius for these triplet emitters [28]. The average distance between dopant molecules $\rho$ can be estimated from the so-called lattice gas model [29] as $\rho=(M / A c \delta)^{1 / 3}$, where $M$ is Btp $2 \operatorname{Ir}$ (acac) molecular weight, $A$ Avogadro's number, $c$ the fractional $\mathrm{Btp}_{2} \mathrm{Ir}$ (acac) concentration, and $\delta$ the sample density. Thus, the suggested Förster mechanism can explain the spectral diffusion effect observed in the present study at 10 wt.\% dopant concentration (Fig. 9b) even though the average 
distance between $\mathrm{Btp}_{2} \operatorname{Ir}(\mathrm{acac})$ at this dopant concentration is $\rho=2.2 \mathrm{~nm}$.

Evidence for the concentration quenching occurring in PS:(10\%)Btp 2 Ir(acac) host-guest system has been presented in Fig. 7, where shortening of the apparent $\mathrm{Ph}$ lifetime to $5.3 \mu$ s was observed comparing to that of $7 \mu$ s for more diluted system. This quenching is definitely related to dopant concentration and not to the $T-T$ annihilation as verified by the linear intensity dependence of Ph upon laser pumping intensity (inset in Fig. 7). The quenching impurity is most probably triplet molecular oxygen which is a notoriously efficient triplet exciton quencher. Indeed, comparison of Ph decay kinetics in oxygen-free encapsulated films and that exposed to the ambient atmosphere (Fig. 9) strongly supports such notion. Encapsulated PS:(10 wt.\%)Btp $\operatorname{Ir}(\mathrm{acac})$ films showed the same mono-exponential $\mathrm{Ph}$ decay with a lifetime of $7 \mu$ s as for diluted system, while the film exposed to air featured an initial fast nonexponential decay (Fig. 9), which is a clear indication of quenching by oxygen. The results presented in Figs. 8 and 9 suggest straightforwardly that the concentration quenching in PS:Btp $\operatorname{Ir}(\mathrm{acac})$ system arises due to the onset of the triplet exciton migration at increased guest molecule concentration and thus their ability to encounter nonradiative oxygen impurity.

It should be mentioned that a significant phosphorescence lifetime shortening due to oxygen was recently reported [7] for another host-guest system, namely MeLPPP doped with platinum-porphyrin dye PtOEP (concentration from $10^{-3}$ to $5 \mathrm{wt} . \%$ ). The effect was explained by reversible formation of a weak complex between PtOEP and oxygen upon exposing sample to air and which quenches the phosphorescence of PtOEP. It was assumed that not mobile but localized guest triplets are involved in the quenching effect [7]. We, however, observed that the oxygen quenching effect on phosphorescence of $\operatorname{Btp}_{2} \operatorname{Ir}(\mathrm{acac})$ depends strongly on the guest concentration (Fig. 7) as no notable lifetime shortening was found at the $1 \mathrm{wt} . \% \mathrm{Btp}_{2} \operatorname{Ir}$ (acac) concentration either in PS or CNPPP host, while at a larger (10 wt.\%) dopant concentration the quenching effect was obvious. A remarkable correlation of the quenching effect with the onset of the spectral diffusion of the phosphorescence of $\operatorname{Btp}_{2} \operatorname{Ir}(\mathrm{acac})$ dispersed in a polymer matrix proves that in the present experiment using $B t p_{2} \operatorname{Ir}(\mathrm{acac})$ dopant the mobile triplets are involved and they are able to reach the oxygen quenching center at sufficiently large dopant concentration. This discrepancy might be rationalized by accounting for considerably shorter intrinsic phosphorescence lifetime of $\mathrm{Btp}_{2} \mathrm{Ir}$ (acac) ( $7 \mu$ s vs. $\sim 100 \mu$ s for PtOEP) and, consequently, for somewhat larger oscillator strength of the radiative transition in this organometallic complex as compared to PtOEP molecule.

Finally, it should be noted that the presented results suggest that the concentration quenching effect, at least at $10 \% \mathrm{Btp}_{2} \operatorname{Ir}$ (acac) concentration level, is definitely due to quenching by impurities like molecular oxygen and not due to the mechanism based on dampening of energy through multiple dipole-dipole energy exchange interaction between neighboring Ir-complex molecules as was suggested before [29]. Indeed, Fig. 8b proves that triplet energy migration does occurs at this dopant concentration, but oxygen-free encapsulated PS:(10 wt.\%)Btp $\operatorname{Ir}$ (acac) films do not show any shortening of the triplet lifetime (Fig. 9). An energy dampening mechanism $[28,30]$ may, however, still be operative at smaller average distances between $\operatorname{Btp}_{2} \operatorname{Ir}(\mathrm{acac})$ molecules.

Further, let us consider Ph properties of $\mathrm{Btp}_{2} \mathrm{Ir}$ (acac) doped into a CNPPP matrix. Time-resolved PL studies of pure CNPPP films have revealed the intrinsic phosphorescence in this polymer and allowed the direct estimation of the triplet energy of $2.3 \mathrm{eV}$ in this material (Fig. 2, curve 2). This implies that the CNPPP host indeed can also efficiently confine triplet excitations of $\mathrm{Btp}_{2} \operatorname{Ir}(\mathrm{acac})$ molecules since the CNPPP triplet level exceeds the guest triplet level at $2.05 \mathrm{eV}$ (Fig. 3). The latter is also supported by observation of the single-exponential Ph decay kinetics in CNPPP: Btp 2 Ir(acac) films featuring a lifetime of $7 \mu$ s at $80 \mathrm{~K}$ (Fig. 5b, curve a), which is virtually the same as has been observed in an optically inert PS host (Fig. 5b, open symbols) at $1 \mathrm{wt} . \%$ dopant concentration.

As it evidenced by Fig. 5b (curve "b"), the decay kinetics deviates from a single exponent at high excitation intensities implying that efficient bimolecular $T-T$ annihilation occurs during the first $10 \mu$ s after the laser pulse. The $T-T$ annihilation leads to the depletion of the reservoir of triplet excitations and therefore the decay kinetics in this time domain does not follow an exponential decay law. Upon lowering the triplet concentration at $t_{d e l}>10 \mu \mathrm{s}$ the kinetics becomes again a monomolecular exponential (Fig. 5b, curve "b").

The onset of the $T-T$ annihilation self-quenching process in CNPPP:Btp 2 Ir(acac) system has been straightforwardly observed in the $\mathrm{Ph}$ intensity dependence measurements (Fig. 5a, curve 2) featuring a crossover from a linear to square-root increase with increasing excitation intensity at about $50 \mu \mathrm{J} /\left(\mathrm{cm}^{2} \times\right.$ Pulse $)$. This kind of saturation usually arises from a bimolecular quenching process which competes with the monomolecular decay and is due to $T-T$ annihilation [18] implying a decrease of the Ph quantum yield at high pump fluence. It cannot be related to the host singlet state since the fluorescence of this host-guest system shows no saturation behavior (Fig. 5a, curve 1). The Ph decay kinetics presented in Fig. 5b agrees well with the $T-T$ annihilation onset observed in Fig. 5a. The excitation intensities at which the decay kinetics (c.f. Fig. 5b) has been measured are shown by arrows in Fig. 5a and they clearly correspond to the linear and the squareroot regime of the excitation intensity plot, respectively.

It worth noting that the excitation intensity effect on the $\mathrm{Ph}$ yield was studied recently for PtOEP doped in MeLPPP host and the $\mathrm{Ph}$ yield was found to decrease at high intensity of the incident light [7]. The observed saturation effect of the dopant phosphorescence at intensities in excess of $\sim 10 \mu \mathrm{J} /\left(\mathrm{cm}^{2} \times\right.$ pulse $)$ was virtually the same regardless whether PtOEP was doped into MeLPPP or optically neutral PS matrix and the phenomenon was explained in terms of bleaching of ground state PtOEP molecules upon population of their triplet state [7]. Such an explanation is definitely not applicable to the $\mathrm{Ph}$ intensity dependence for CNPPP:Btp $\mathrm{P}_{2} \operatorname{Ir}(\mathrm{acac})$ observed in the present paper as the dominance of bleaching effect is at variance with (i) the observation of the obvious deviation of the $\mathrm{Ph}$ decay kinetics from a single exponent at high excitation intensities (Fig. 5), which, on the other hand, nicely agrees with the $T-T$ annihilation mechanism; (ii) no decrease of $\mathrm{Ph}$ yield of $\mathrm{Btp}_{2} \mathrm{Ir}$ (acac) was found when it was imbedded in neutral PS matrix and in frozen diluted solution up to the pumping intensity of $\sim 500 \mu \mathrm{J} /\left(\mathrm{cm}^{2} \times\right.$ pulse); (iii) the crossover from a linear to squareroot increase of the Ph intensity dependence in CNPPP:Bt $\mathrm{P}_{2} \operatorname{Ir}(\mathrm{acac})$ host-guest system tends to shift to a lower pumping intensities with increasing temperature, thus pointing on importance of triplet exciton diffusion process. Thus, the reduction of the $\mathrm{Ph}$ yield in CNPPP:Btp 2 Ir(acac) system at high excitation intensity is most probably governed by the triplet-triplet annihilation mechanism which predominates over the possible bleaching effect of Btp2 Ir(acac) ground state. The latter effect in the present system might certainly be possible at larger excitation intensity.

The question arises which triplets, of the host or of the guest, are responsible for the $T-T$ annihilation quenching in the CNPPP:Btp 2 Ir(acac) system. The results obtained on $B \mathrm{tp}_{2} \operatorname{Ir}(\mathrm{acac})$ doped into PS host suggest that at $1 \%$ doping the guest triplet excitation must be confined by both polymer hosts used in this study. At such low concentration, guest triplet migration is not possible, in other words, guest triplets are immobile. Therefore, $T_{\text {guest }}-T_{\text {guest }}$ annihilation is impossible. On the other hand, all CNPPP host triplet excitons are eventually transferred to the phosphorescent guest as proven by the complete quenching of the intrinsic CNPPP phospho- 
rescence (Fig. 4). This precludes $T_{\text {host }}-T_{\text {host }}$ annihilation at not very small dopant concentration. Therefore we conclude that the observed $T-T$ annihilation proceeds via a $T_{\text {guest }}-T_{\text {host }}$ annihilation reaction, i.e., when a mobile host triplet encounters a localized guest triplet excitation. This picture is in agreement with the absence of $T-T$ annihilation quenching for $B_{2} \mathrm{P}_{2} \operatorname{Ir}$ (acac) doped in PS host at the same concentration level, since excited host triplets are missing in this case. It should be mentioned that bimolecular heteroannihilation between triplet excitons of a polymer and triplet excitations of dopant was already assumed before to occur also in MeLPPP:PtOEP host-guest system [6].

Another remarkable result of this study is observation of a "delayed phosphorescence" in CNPPP:Btp2Ir(acac) films at time delays after the laser pulse that are orders of magnitude lager than the natural lifetime of triplet excitations of the Btp $2 \operatorname{Ir}(\mathrm{acac})$ complex. As one can see from Fig. 4, after the initial decay of the relatively short-lived guest phosphorescence featuring the lifetime of $7 \mu \mathrm{s}$ at $80 \mathrm{~K}$, the Ph decay kinetics shows a very long tail lasting up to milliseconds. This is definitely a delayed Ph emission. It may have two plausible origins: (i) delayed arrival of intrinsically long-lived host triplets to the $\mathrm{Btp}_{2} \operatorname{Ir}(\mathrm{acac})$ guest molecules, or (ii) delayed production of guest triplets by delayed recombination of (trapped) charge carriers on $B_{p_{2}} \operatorname{Ir}(\mathrm{acac})$ guest molecules. Below we discuss these two different routes.

Besides the delayed guest $\mathrm{Ph}$, intensive delayed fluorescence (DF) of the CNPPP host has also been observed in the delayed emission spectra of CNPPP:(0.05 wt.\%)Btp $\mathrm{Bt}_{2} \mathrm{Ir}$ (acac) films (Fig. 4). The above spectra were measured at large integration time (gate width) of $1 \mathrm{~ms}$. The DF in these films (as well as in pristine CNPPP films) arises most probably due to $T_{\text {host }}-T_{\text {host }}$ annihilation as (i) the intensity dependence of the DF varies almost quadratically with the excitation laser intensity (not shown here) implying a bimolecular mechanism of population of the singlet level, (ii) $\mathrm{Ph}$ of the guest is a linear function of the pumping intensity, and (iii) the CNPPP film shows intrinsic long-lived triplet excitations detected even in the millisecond time domain (Fig. 2). These factors seem to favor of the mechanism of delayed arrival of host triplets as the main cause for delayed phosphorescence. However, at higher $\mathrm{Btp}_{2} \operatorname{Ir}(\mathrm{acac})$ concentration the DF emission of the host decreases dramatically. This is in good agreement with the mechanism of $T_{\text {host }}-T_{\text {host }}$ annihilation as source of the DF. Indeed, as guest molecules readily accept triplets from the host, where they rapidly decay, it is expected that the apparent host triplet lifetime and their population strongly decreases with increasing dopant concentration of the guest. Therefore, the intensity of delayed $T_{\text {host }}-T_{\text {host }}$ annihilation, and therefore DF, is reduced at higher doping concentrations.

It should be noted that the decay kinetics of the long-lived component (delayed phosphorescence) in CNPPP:Btp ${ }_{2} \operatorname{Ir}(\mathrm{acac})$ system was found to be virtually the same for different $B t p_{2} \operatorname{Ir}(\mathrm{acac})$ dopant concentrations ranging from 0.05 to $5 \mathrm{wt}$.\%. For the mechanism based on delayed arrival of host triplet excitations one should contrary expect that the decay of the above slow component becomes much faster with increasing dopant concentration because of the host triplets trapping by the triplet-emitter dopant enhances considerably in such case. We remark that increasing the $B t p_{2} \operatorname{Ir}(a c a c)$ dopant concentration has almost no effect on the delayed phosphorescence in CNPPP:Btp ${ }_{2} \operatorname{Ir}(\mathrm{acac})$ films (including also a relatively high dopant concentration), therefore we are forced to conclude that the delayed production of guest triplets occurs mainly via a delayed recombination of charge carriers on Btp $\mathrm{P}_{2} \mathrm{Ir}$ (acac). Such efficient delayed charge-carrier recombination could be ensured by trapped charge carriers and most probably is a dominant mechanism for the delayed $B_{2} p_{2} \operatorname{Ir}(\mathrm{acac})$ phosphorescence. It is therefore important to elucidate the origin of charge trapping CNPPP:Btp ${ }_{2} \operatorname{Ir}$ (acac) host-guest system.
TSL results presented in Fig. 10 do testify that $B t p_{2} I r(a c a c)$ molecules create a quite deep hole traps in CNPPP matrix with a trap depth of $\sim 0.6 \mathrm{eV}$. Trapped geminate electron-hole pairs then can be readily generated when a hole is trapped on $B_{2} p_{2} \operatorname{Ir}(\mathrm{acac})$ molecules and an electron is localized on some shallower intrinsic traps of the CNPPP polymer. Such trapped geminate pairs should be more stable against recombination and depending on mutual separation between opposite sign charge carriers they could survive for milliseconds or even seconds [13,31]. Since the recombination occurs directly on (or in the vicinity of) the dopant sites initiated by a trapped hole, it is natural that it produces guest phosphorescence which follows the charge recombination kinetics.

Charge carrier trapping by $\mathrm{Btp}_{2} \operatorname{Ir}(\mathrm{acac})$ molecules can excellently explain more efficient quenching of the host fluorescence component in the electroluminescence spectra of CNPPP:Btp $\operatorname{Ir}(\mathrm{a}-$ cac) OLEDs as compared to the situation in photoluminescent spectra (c.f. Fig. 3a and b). It should be noted that the charge trapping argument has been often used before to explain this phenomenon $[22,23]$; however in the present paper we present direct evidence by means of charge trapping spectroscopy that the phosphorescent metal-organic complexes do act as charge traps where the trap depth is determined by the difference in corresponding HOMOs of the host and guest. It proves that metal-organic complexes affect charge trapping similarly to all-organic small molecules.

\section{Conclusion}

The results show that the decrease in the $\mathrm{Ph}$ efficiency in CNPPP:Btp $2 \operatorname{Ir}(\mathrm{acac})$ system at increasing excitation intensity is dominated by mutual host-guest triplet-triplet annihilation. We have observed spectral diffusion effects at $10 \mathrm{wt}$ \% of $\mathrm{Btp}_{2} \operatorname{Ir}(\mathrm{acac})$ dispersed in a polymer matrix, which is a direct proof for the triplet excitons migration though the manifold triplet-emitter sites at such dopant concentration level. This suggests straightforwardly that the concentration quenching in PS:Btp2Ir(acac) system arises due to the onset of the triplet exciton migration at increased guest molecule concentration and thus their ability to encounter nonradiative oxygen impurity. The obtained results are in excellent agreement with the recently proposed mechanism of dipole-dipole long-range Forster energy transfer in such phosphorescent materials [28]. A "delayed phosphorescence" was found in CNPPP:Btp $2 \operatorname{Ir}(\mathrm{acac})$ films, which emerges at the time delay orders of magnitude lager than the natural lifetime of triplet excitations of $B t p_{2} \operatorname{Ir}(a c a c)$ complex, and is due to delayed production of guest triplets by recombination of trapped charge carriers on $B t p_{2} \operatorname{Ir}(\mathrm{acac})$ guest molecules. The latter was supported by TSL measurements which provided direct evidence that the triplet emitters create hole traps in conjugated polymers. A good agreement between experimentally obtained trap depth and that predicted from difference in HOMO levels is found for CNPPP:Btp ${ }_{2} \operatorname{Ir}$ (acac) host-guest system.

\section{Acknowledgments}

One of the authors, S. Schols, thanks the FWO-Vlaanderen for financial support. The research was also supported by the program of fundamental research of the National Academy of Science of Ukraine, "Nanostructured systems, nanomaterials, nanotechnologies" through the Project No. 10/09-H.

\section{References}

[1] M.A. Baldo, D.F. O’Brien, M.E. Thompson, S.R. Forrest, Phys. Rev. B 60 (1999) 14422.

[2] C. Adachi, M.A. Baldo, M.E. Thompson, S.R. Forrest, J. Appl. Phys. 90 (2001) 5048.

[3] V. Cleave, G. Yahioglu, P. Le Barny, R.H. Friend, N. Tessler, Adv. Mater. 11 (1999) 285. 
[4] V. Cleave, G. Yahioglu, P. Le Barny, D.H. Hwang, A.B. Holmes, R.H. Friend, N. Tessler, Adv. Mater. 13 (2001) 44.

[5] R.W. Higgins, A.P. Monkman, H.-G. Nothofer, U. Scherf, J. Appl. Phys. 91 (2002) 99.

[6] S.A. Bagnich, H. Bassler, Chem. Phys. Lett. 381 (2003) 464.

[7] S.A. Bagnich, C. Im, H. Bassler, D. Neher, U. Scherf, Chem. Phys. 299 (2004) 11.

[8] S.A. Bagnich, H. Bassler, D. Neher, J. Chem. Phys. 121 (2004) 9178.

[9] Yu. Romanovskii, H. Bassler, Chem. Phys. Lett. 326 (1999) 51.

[10] F. Laquai, C. Im, A. Kadashchuk, H. Bassler, Chem. Phys. Lett. 375 (2003) 286.

[11] A.P. Monkmann, H.D. Burrows, I. Hamblett, S. Navaratnam, U. Scherf, C. Schmitt, Chem. Phys. Lett. 327 (2000) 111.

[12] M.A. Baldo, C. Adachi, S.R. Forrest, Phys. Rev. B 62 (2000) 10967.

[13] A. Kadashchuk, Yu. Skryshevski, A. Vaknin, N. Ostapenko, E.V. Emelianova, V.I. Arkhipov, H. Bassler, Phys. Rev. B 63 (2001) 115205.

[14] A. Kadashchuk, Yu. Skryshevski, Yu. Piryatinski, A. Vakhnin, E.V. Emelianova, V.I. Arkhipov, H. Bassler, J. Shinar, J. Appl. Phys. 91 (2002) 5016.

[15] Yu.V. Romanovskii, A. Gerhard, B. Schweitzer, U. Scherf, R.I. Personov, H. Bassler, Phys. Rev. Lett. 84 (2000) 1027.

[16] Yu.V. Romanovskii, H. Bassler, Chem. Phys. Lett. 326 (2000) 51.

[17] S.A. Patil, U. Scherf, A. Kadashchuk, Adv. Funct. Mater. 13 (2003) 609.

[18] D. Hertel, H. Bassler, R. Guentner, U. Scherf, J. Chem. Phys. 115 (2001) 10007.
[19] A.P. Monkman, H.D. Burrows, L.J. Hartwell, L.E. Horsburgh, I. Hamblett, S. Navaratnam, Phys. Rev. Lett. 86 (2001) 1358.

[20] C. Adachi, M.A. Baldo, S.R. Forrest, S. Lamansky, M.E. Thompson, R.C. Kwong, Appl. Phys. Lett. 78 (2001) 1622.

[21] S. Lamansky, P. Djurovich, D. Murphy, F. Abdel-Razzaq, H.-E. Lee, C. Adachi, P.E. Burrows, S.R. Forrest, M.E. Thomson, J. Am. Chem. Soc. 123 (2001) 4304.

[22] W. Zhu, Y. Mo, M. Yuan, W. Yang, Y. Cao, Appl. Phys. Lett. 80 (2002) 2045.

[23] H.-M. Liu, J. He, P.-F. Wang, H.-Z. Xie, X.-H. Zhang, C.S. Lee, B.-Q. Sun, Y.-J. Xia, Appl. Phys. Lett. 87 (2005) 221103.

[24] I. Tanaka, Y. Tabata, S. Tokito, Jpn. J. Appl. Phys. 43 (2004) L1601.

[25] A. Kadashchuk, A. Vakhnin, Yu. Skryshevski, V.I. Arkhipov, E.V. Emelianova, H. Bassler, Chem. Phys. 291 (2003) 243.

[26] Y.D. Jin, Ph.D. Thesis, IMEC, Belgium, 2002.

[27] B.W. D'Andrade, S. Datta, S.R. Forrest, P. Djurovich, E. Polikarpov, M.E. Thompson, Org. Electron. 6 (2005) 11.

[28] Y. Kawamura, J. Brooks, J.J. Brown, H. Sasabe, C. Adachi, Phys. Rev. Lett. 96 (2006) 017404.

[29] P.M. Borsenberger, D.S. Weiss, Organic Photoreceptors for Imaging Systems, Dekker, New York, 1993.

[30] H. Kuhn, J. Chem. Phys. 53 (1970) 101.

[31] V.R. Nikitenko, D. Hertel, H. Bassler, Chem. Phys. Lett. 348 (2001) 89. 